\title{
CARICATURA NA DESTERRO DO SÉCULO XIX \\ O Periódico Crítico Matraca
}

Fabiana Machado Didoné

\section{RESUMO}

O Periódico Crítico Matraca circulou em Nossa Senhora do Desterro no período de 1881 a 1886, registrando, com humor e crítica, acontecimentos políticos, sociais e culturais, como também as peculiaridades da vida da cidade. Esse periódico, editado pela Oficina de Tipografia e Litografia de Alexandre Margarida, tinha como ilustrador e caricaturista seu filho, Joaquim Margarida. Durante o século XIX, era prática comum entre artistas do Brasil e do exterior se valer da caricatura e da sátira como instrumento para representar com ironia os acontecimentos da sua época. A caricatura e sátira, gênero que combina arte, crítica e humor, fornecem um rico e pouco explorado material que possibilita compreender as relações sociais, culturais e políticas de uma sociedade.

Palavras Chave

Caricatura, periódico crítico, Desterro.

\begin{abstract}
The journal Critical Matraca circulated in Nossa Senhora do Desterro in the period 1881 to 1886, recording with humor and criticism, political, social and cultural as well as the peculiarities of city life. This journal, published by the Oficina de Tipografia e Litografia de Alexandre Margarida, had as an illustrator and cartoonist his son, Joaquim Margarida. During the nineteenth century it was common practice among artists in Brazil and abroad take advantage of caricature and satire as a tool to represent irony in the events of his time. The caricature and satire, genre that
\end{abstract}


combines art, criticism and humor, provide a rich and unexplored material allowing to understand the social, cultural and political society.

Key words

Caricature, critical jornal, Desterro.

A caricatura é uma representação gráfica ou plástica de uma pessoa, ideia ou acontecimento interpretada propositalmente de forma distorcida e exagerada, acentuando ou revelando aspectos específicos. Já a sátira, desenvolvida primeiramente na forma literária, se utiliza da caricatura para fazer julgamentos morais. A sátira social está concentrada em cidadãos comuns e situações cotidianas, já a sátira política, ridiculariza figuras públicas e reage a eventos e polêmicas políticas da época em questão ${ }^{1}$. A caricatura e a sátira, uma combinação de arte, crítica e humor, possibilitam conhecer e compreender as relações sociais, políticas e culturais de uma sociedade. Impiedosos ou amenos, cruéis ou generosos, os caricaturistas, com poucas linhas em uma folha em branco, são capazes de retratar toda uma época.

O aparecimento da caricatura no Brasil está vinculado ao surgimento e desenvolvimento da imprensa, na primeira metade do século XIX. A vinda da família real portuguesa para o Brasil em 1808 e a abertura dos portos propiciou o estabelecimentos das primeiras oficinas gráficas no país, gerando a impressão de livros e periódicos ainda sem material ilustrativo. Com a instalação de oficinas tipográficas e litográficas, a imprensa teve um impulso e, consequentemente, houve a multiplicação de publicações de jornais e periódicos, dentre eles, folhas satíricas e

\footnotetext{
${ }^{1}$ McPHEE, Constance et ORENSTEIN, Nadine (org.). Infinite Jest: caricature and satire from Leonardo to Levine. The Metropolitan Museum of Art: New York, 2011, p. 61
} 
críticas $^{2}$. As primeiras folhas satíricas conhecidas a circular no Brasil foram 0 Escorpião, O Meteoro e O Pensador, sendo compostas apenas com textos humorísticos. As caricaturas, inicialmente, eram apresentadas em pranchas soltas com pouca qualidade, sendo sua divulgação feita de forma precária e suas restritas cópias chegavam a poucos privilegiados. Porém, com as inovações técnicas no campo da gravura em meados do século XIX, as caricaturas passaram a ser incorporadas aos periódicos, possibilitando ampliar sua tiragem, seu alcance e sua influência.

A primeira caricatura que circulou no Brasil como estampa avulsa data de 1837 e retratava um funcionário do governo recendo propinas referente ao Correio Oficial, sendo atribuída a Manoel de Araújo Porto Alegre (1806-1879). O periódico Lanterna Magica que circulou no Rio de Janeiro entre os anos de 1844 e 1845 marca o início das publicações ilustradas com caricaturas impressas. Periódico destinado às letras, às artes plásticas, à crítica e à polêmica, circulava semanalmente, tinha como diretor Manoel de Araújo Porto Alegre e como caricaturista Rafael Mendes de Carvalho. Dentre os periódicos que mais se destacaram no país, estão a Semana Ilustrada, desenhada e litografada por Henrique Fleuiss; O Mosquito, com desenhos de Cândido de Faria e a Revista Ilustrada, editada por Ângelo Agostini. A Semana Ilustrada circulou no Rio de Janeiro entre os anos de 1860 a 1876, publicando poesias, crônicas e contos de escritores e jornalistas da época, entre outros, Machado de Assis, Joaquim Manoel de Macedo e Bernardo Guimarães. Já O Mosquito, cujo subtítulo era Jornal Caricato e Crítico, dava grande ênfase à crítica política e circulou no período de 1869 a 1877. Porém, a Revista Ilustrada foi a que alcançou maior popularidade, com grande tiragem era distribuída nas principais províncias regularmente. Esses periódicos críticos e satíricos se propunham, através do humor, censurar, corrigir ou ironizar atitudes, ideias, valores e pessoas. Exerceram importante papel, tanto como meio de informação como objeto de questionamento e protesto.

\footnotetext{
${ }^{2}$ ANDRADE, Joaquim M. F. de. História da Fotorreportagem no Brasil: a fotografia na imprensa do Rio de Janeiro de 1839 a 1900. Rio de Janeiro: Elsevier, 2004, p.29
} 
Repetindo o fato que aconteceu nas principais cidades do país, na cidade de Nossa Senhora do Desterro (atual Florianópolis), a partir da década de 1850, proliferou a edição e circulação de jornais e periódicos, sendo os principais enfoques a polêmica política e o processo civilizador. Esses jornais estavam ligados aos partidos políticos da época, vivendo à sombra deles e dos embates e polêmicas gerados pela política local ${ }^{3}$. Os artigos e crônicas jornalísticas focavam a sociabilidade e a vida familiar e funcionavam como forma de propagar princípios racionais e normas de comportamento, que, aos poucos, eram interiorizados pela sociedade local. Os jornais e periódicos eram os principais meios de informação, exercendo importante papel na formação sócio-cultural do povo.

Eminentemente políticos, eram também noticiosos, comerciais e literários: propagavam o ideal iluminista de liberdade de expressão e de amor ao progresso. Viam-se como um dos principais instrumentos de ligação entre o mundo ilustrado da civilização e o mundo rude da fronteira, da qual eram a mais viva voz ${ }^{4}$.

O Periódico Crítico Matraca circulou na cidade de Desterro entre os anos de 1881 a 1886, registrando, com humor e crítica, acontecimentos políticos, sociais e culturais, como também as peculiaridades da vida da cidade. Nos três primeiros anos, era editado no formato $24 \times 18 \mathrm{~cm}$, com apenas quatro páginas contendo apenas textos, sem ilustrações. Era publicado todas as quintas e domingos, trazendo sempre num tom crítico e debochado notícias sobre a cidade, além de poesias, piadas e charadas e anúncios. A partir do ano de 1884, com periodicidade semanal, ampliou seu formato para $30 \times 25 \mathrm{~cm}$ e passou a incluir ilustrações. Na sua formatação padrão, uma ilustração ocupava toda primeira página, sendo o tema uma

\footnotetext{
${ }^{3}$ SIEBERT, Itamar. Critica jornalística, sociabilidade e vida familiar na Desterro de meados do século XIX. In: BRANCHER, Ana e AREND, Silvia Mara Favero (org.). História de Santa Catarina no século XIX. Florianópolis: Ed. Da UFSC, 2001, p.232

${ }^{4}$ SIEBERT, 2001, Op. Cit., p. 235
} 
crítica bem humorada sobre um acontecimento político, social ou cultural do momento, como mostra as figuras 01,02 e 03. As páginas centrais eram divididas em seções apenas com textos, iniciando com "Expediente" informando o valor das assinaturas, seguindo com a seção "A Matraca" com um texto do editor do periódico, depois com a seção "Factos e Boatos" com pequenas notícias sobre a cidade e seus habitantes. As outras seções se alternavam em cada edição, eram elas, "Secção Crítica", "Secção Livre", "Secção Amigável", "Secção Poética" e "A pedidos". A última página era ocupada novamente uma ilustração sobre algum tema recorrente da época.

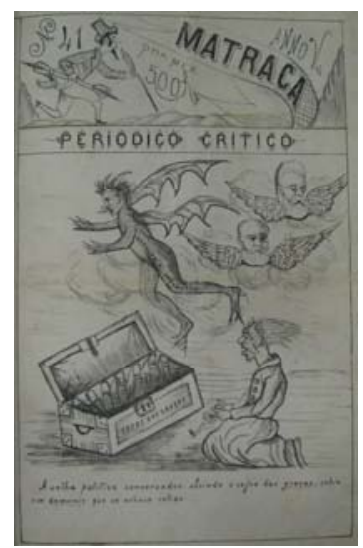

Fig.01: Periódico Matraca

Ano V, edição 41

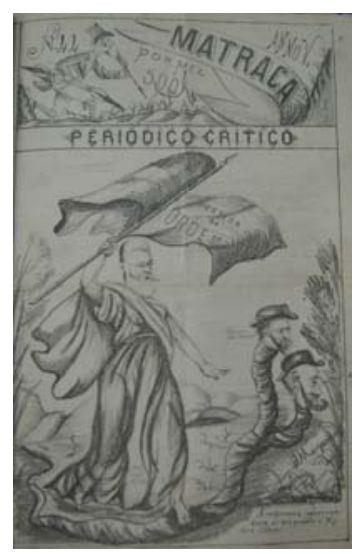

Fig.02: Periódico Matraca

Ano V, edição 44

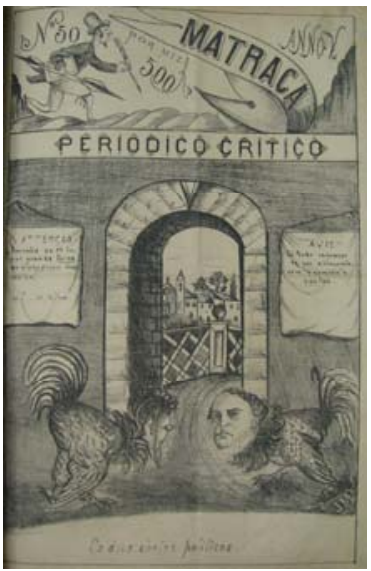

Fig.03: Periódico Matraca Ano V, edição 50

Fonte das fig. 01, 02 e 03: Biblioteca Publica do Estado de Santa Catarina

O Periódico Critico Matraca era editado pela Officina de Lithographia e Typhographia de Alexandre Francisco das Oliveiras Margarida, estabelecida em Desterro no ano de 1870, conforme anuncio que aparece na figura 04. Alexandre Margarida (1838-1916) editava em sua tipografia jornais, periódicos, semanários, partituras musicais dentre outros documentos. Grande parte de suas publicações estavam envolvidas com causas sociais e politicas, como o semanário Artista em 1882, que propagava ideias republicanas e o jornal Regeneração que, na década de 1870, participou ativamente a favor da abolição. Foi um dos fundadores do Liceu de Artes e Ofícios em 1883, onde também atuou como professor de desenho, litografia, 
tipografia e encadernação. Seu filho, Joaquim Antônio das Oliveiras Margarida (1865-1955) era o ilustrador e caricaturista do Periódico Critico Matraca. Assim como o pai, foi nomeado professor do Liceu de Artes e Ofícios para desenho, caligrafia e geometria. Retratava pessoas influentes da cidade e em 1892, ilustrou outro periódico, o Distração. Segundo o crítico Osmar Pisani, os irmãos Margarida [Manoel e Alexandre], " (...) que faziam desenho de humor e tinham uma escola de desenho, juntamente com o pintor Sebastião Fernandes movimentaram a pacata Desterro, criando um pequeno núcleo de artistas plásticos ${ }^{5 "}$.

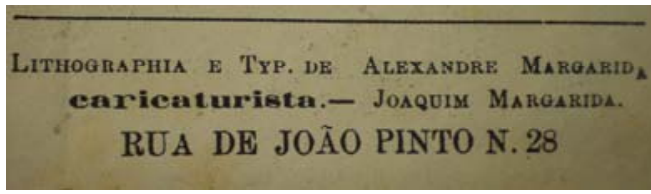

Figura 04: Anuncio da Litografia e Tipografia de Alexandre Margarida

Extraído do Periódico Crítico Matraca de 11/03/1888, ano 8, no. 7

Fonte: Biblioteca Publica do Estado de Santa Catarina

A partir do século XIX, os esforços com a caricatura se tornaram mais constantes, era prática comum entre artistas do Brasil e do exterior se valer da caricatura e da sátira como instrumentos para representar, com ironia, humor e crítica, pessoas e acontecimentos da sua época. Quando artistas reconhecidos pela Academia desenhavam propositalmente faces exageradas e corpos deformados, não estavam caracterizando falta de domínio técnico ou descuido, mas sim desafiando padrões estabelecidos de harmonia, beleza e proporção. Diversos artistas consagrados, em algum momento de sua carreira, fizeram caricatura, dentre eles Leonardo da Vinci, Toulouse-Lautrec, Delacroix e Claude Monet. Independente do contexto histórico ou da intenção, artistas tem tradicionalmente voltado a repertórios de composição padrão e fórmulas visuais para ajudá-los a compor os elementos caricaturais nas ilustrações de humor. Dentre esses repertórios, vale

\footnotetext{
${ }^{5}$ PISANI, Osmar. Arte Catarinense: uma paisagem em transformação. In: CORREA, Carlos Humberto P. Et al. (org.). A realidade catarinense no século XX. Florianópolis: Instituto Histórico e Geográfico de Santa Catarina, 2000, p.97
} 
destacar o exagero e distorção de rostos e corpos e a representação de pessoas como aninais e objetos. Esses repertórios podem ser observados em caricaturas anteriores ao século XIX, estendendo-se ate os dias atuais.

A caricatura tem sido, através da história, voz contundente e impiedosa que, mesmo sob as condições severas da censura, usando a linguagem metafórica, subversiva e velada da ironia, da sátira, do sarcasmo e do trocadilho, denuncia e reivindica os sofrimentos dos oprimidos. A caricatura é portanto, arma aguçada que o povo aplaude ao ver ridicularizadas nela a forca, o despotismo, o autoritarismo, a intolerância, a injustiça ${ }^{6}$.

A distorção de elementos físicos, como desproporção entre cabeça e tronco, membros alongados ou curtos demais, saliência e exagero de características faciais, entre outros, formam o repertório mais utilizado para compor uma caricatura. Leonardo Da Vinci, no século XV, realizou vários desenhos de pequeno formato de cabeças grotescas, provavelmente como estudos de fisionomias, mas que pode ser considerado um dos precedentes da caricatura. De acordo com Giorgio Vasari? Leonardo, que tinha grande interesse pela ciência e também por tudo o que fosse estranho, era fascinado por pessoas com faces bizarras e frequentemente as seguia para memorizar suas características e depois desenhá-las. Essas faces bizarras ou cabeças grotescas são elementos constantes, aparecem tanto nas gravuras do artista alemão Wenceslaus Hollar no século XVII (figura 05), o qual pesquisava os estudos de Leonardo Da Vinci. Como também nos desenhos caricatos de artistas do século XIX, como na caricatura de Joaquim Margarida (figura 06), extraída do Periódico Matraca, ano 5, no. 52 de 1885. As deformidades e desproporções no desenho da figura humana também são recorrentes nos desenhos caricatos durante

\footnotetext{
${ }^{6}$ FONSECA, Joaquim da. Caricatura: a imagem gráfica do humor. Artes e Ofícios Editora Ltda.: Porto Alegre, 1999, p.13

${ }^{7}$ VASARI, Giorgio. Vida dos artistas. Edição de Lorenzo Torrentino. São Paulo: Editora WMF Martins Fonte, 2011, p.450
} 
séculos, se apresentando das mais diversas formas. Um exemplo do século XVIII, é o desenho a carvão do artista francês Francois-Andre Vincent, que durante sua estada na Academia francesa, realizou inúmeras caricaturas de artistas e amigos. Na obra Caricature of the painter Pierre-Charle Jombert (figura 07), ele reduziu o tamanho da cabeça e ampliou o tamanho das mãos do pintor. Na litografia de Joaquim Margarida publicada no Periódico Crítico Matraca do ano V, edição 47 (figura 08), também fica evidente a desproporção no desenho da figura humana, principalmente no formato alongado do nariz.

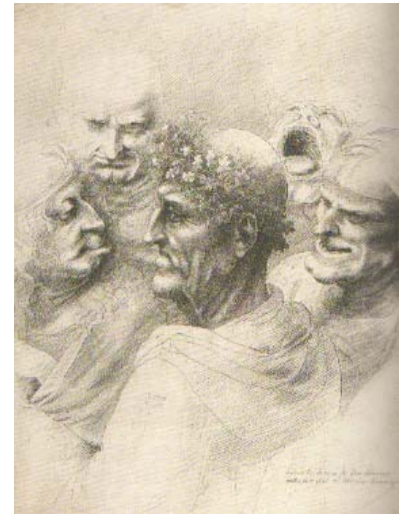

Fig.05: W. Hollar, Five Grotesque Heads,1646

Litografia - 24,6×18,7cm

Fonte: www.metmuseum.org

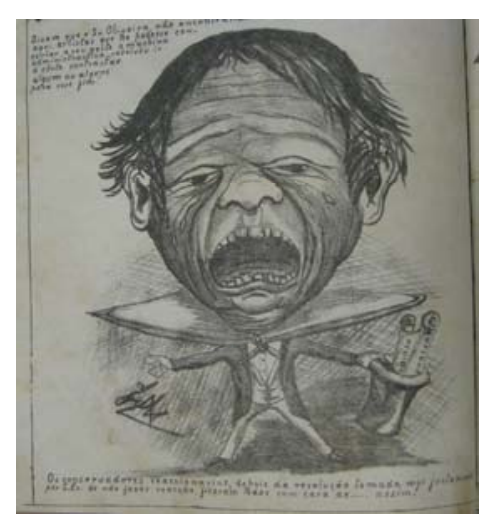

Fig. 06: Joaquim Margarida, 18 Litografia - Matraca, ano V, ed.52 Fonte: Biblioteca Publica de SC 


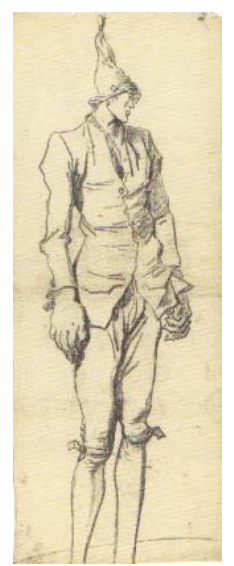

Fig.07: F.A. Vincent, Caricature of..., 1775

Desenho a carvão - 106x42cm

Fonte: www.metmuseum.org

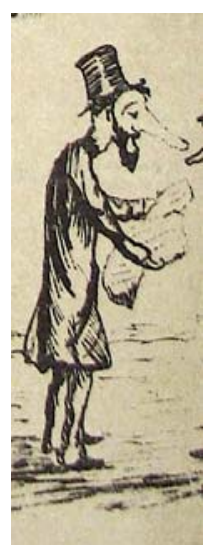

Fig.08: J. Margarida, 1885

Litografia - Matraca, ano V, ed.47

Fonte: Biblioteca Publica de SC

Outro repertório muito utilizado nas caricaturas são as criaturas híbridas compostas de pessoas-animais e pessoas-objetos. O artista francês Francois Desprez, no século XVI criou um pequeno livro com 120 ilustrações de figuras híbridas de pessoas-animais com o título Les Songes Drolatiques de Pantagruel; Henry Louis Stephens, artista americano realizou uma série de litografias chamada The Comic Natural History of the Human Race na década de 1850, onde explora figuras com cabeça humana em corpo de animal, entre eles pássaros, insetos e peixes (figura 09). No Periódico Matraca, encontra-se diversas ilustrações feitas por Joaquim Margarida em que ele utiliza este repertório. Na figura 10, extraída do periódico de número 7 , ano 8 , o artista desenha criaturas com corpo humano e cabeça de animal. Os híbridos homem-objeto também vêm de uma longa tradição nos desenhos de humor. $\mathrm{O}$ artista francês Clement Pruche na litografia Fameux jury of peinture. Salon de 1841 (figura 11) representa estranhas figuras com corpos humanos e cabeças com os mais variados tipos de objetos como: jarros, ossos, potes e verduras. Esta gravura faz uma crítica ao júri do Salão de 1841 e foi publicado no jornal satírico Le Charivari. Já no século XX, Ronald Searle, realiza um desenho de um homem degustando uma taça de vinho, porém sua cabeça é de madeira e seu bigode de vegetal, o título da obra é A discernable touch of oak (figura 12). A partir do momento que as caricaturas começaram a ser produzidas como múltiplos e passaram a circular com mais facilidade e abrangência, os repertórios 
clássicos e padrões visuais puderam facilmente passar de um artista a outro e influenciar gerações futuras.

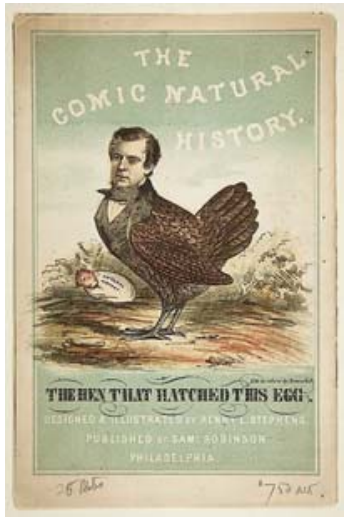

Fig. 09: Henry Stephens, The Comic Natural..., 1851

Litografia a cores $-28,6 \times 18,4 \mathrm{~cm}$

Fonte: www.metmuseum.org

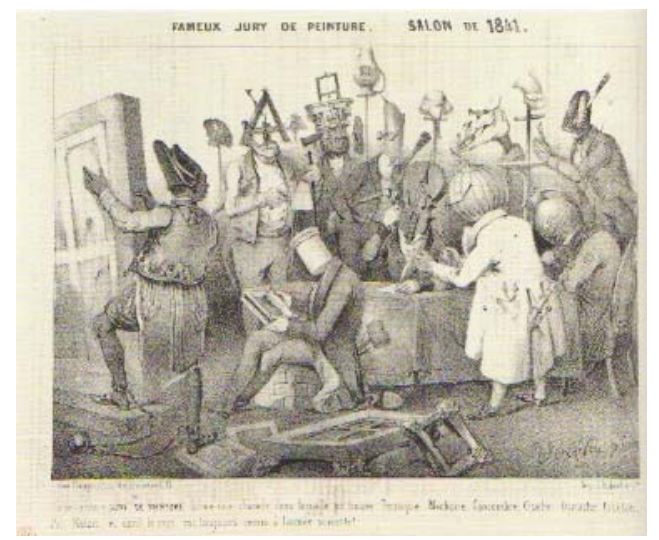

Fig.11: C. Pruche, Fameux jury of peintre, 1841

Litografia - 30×36cm

Fonte: www.metmuseum.org

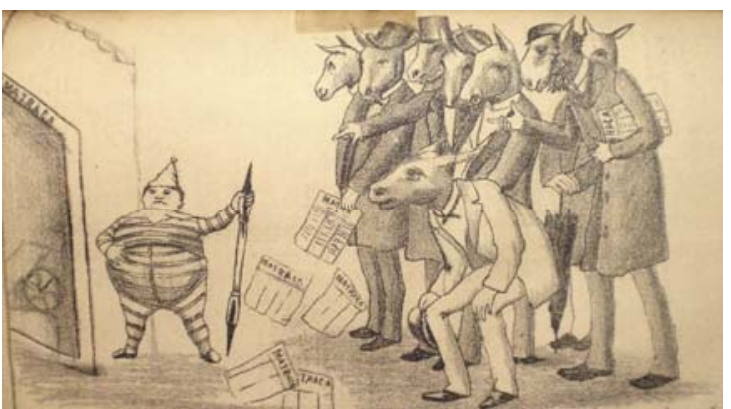

Fig. 10: Joaquim Margarida, 1888

Litografia - Matraca, ano VIII, ed.08

Fonte: Biblioteca Publica de SC

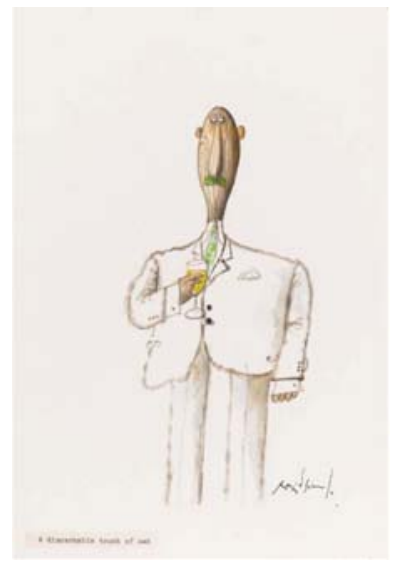

Fig.12: R. Searle, A discernable touch of oak, 1950 Lápis e aquarela sobre papel - 32×22cm

Fonte: www.metmuseum.org

Nas sátiras, social e política, encontra-se elementos textuais compostos com as ilustrações. Citações e trocadilhos são colocados como títulos e versos são comumente usados para fortalecer e evidenciar a imagem. Algumas ilustrações são 
acompanhadas de textos explicativos que reforçam sua interpretação e entendimento. Ridicularizando uma ampla gama de ações e comportamentos humanos, a sátira social geralmente apresenta indivíduos comuns e deriva seu humor de situações cotidianas. Demonstrações de luxúria, gula, voracidade, ganância, preguiça e soberba ocorrem frequentemente em desenhos e impressões satíricas. Alguns dos temas mais populares nas sátiras sociais são: os jogos de cartas, onde se apresentam as cenas de mesa de jogos com as disputas, as trapaças, as brigas, os vencedores e os perdedores; a moda, com destaque para os padrões de cada época, ridicularizando as perucas, os trajes e todos os excessos desse setor; os hábitos de comer e beber, com cenas bizarras de refeições; as multidões nas apresentações de teatro; e por último, o mundo da arte, retratando estúdios de artistas, obras, exposições e salões de arte. O artista francês HonoreVictorin Daumier criou uma série de sátiras tematizando os Salões de arte da época, no século XIX. Caricaturou os visitantes, o júri e os artistas participantes dos salões, tanto a alegria dos que haviam sido aceitos como a decepção dos rejeitados. Em uma das litografias da serie L'Exposition de 1859, publicada nos periódico satírico francês Le Charivari, representa a indignação do artista François Bonwin que teve uma obra rejeitada naquela exposição (figura 13). No Brasil, Ângelo Agostini publicava na Revista Ilustrada, no século XIX, caricaturas e comentários irônicos sobre os salões de arte e sobre alguns artistas, sendo Victor Meirelles um de seus favoritos. Na figura 14, a ilustração publicada na Revista llustrada de 25/04/1879 é oferecida à Victor Meirelles e representa duas telas do pintor, onde personagens saem de uma tela e entram em outra.
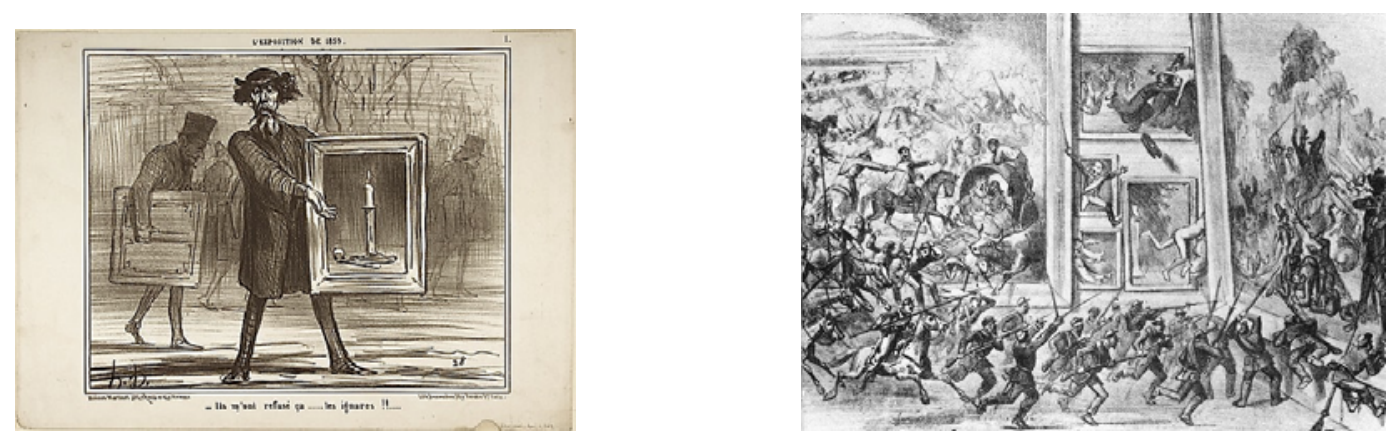
Fig.13: H. Daumier, L'Exposition, 1859

Litografia $-26 \times 36 \mathrm{~cm}$

Fonte: www.metmuseum.org
Fig.14: A. Agostini, 1879

Litografia - publicada na Revista Ilustrada Fonte: www.catalogodasartes.com.br

O humor e a caricatura, mesmo de forma sutil, são uma poderosa arma de protesto, contestação e subversão. A caricatura e a sátira não só exprimem o ponto de vista de seu autor, mas também refletem a opinião publica, tornando-se uma importante e temida forma de expressão. Para Fonseca ${ }^{8}$, as caricaturas e as sátiras ocupam espaço privilegiado em jornais e revistas de todo mundo por serem comentários sociais velados pela ironia e pelo sarcasmo, mostrando com simples figuras o que não poderia ser dito com mil palavras.

Não se pode negar a importância do desenho humorístico na imprensa, seja como documento histórico, como fonte de informação social e politica, como termômetro de opinião, como fenômeno estético, como expressão artística literária ou como simples forma de diversão e passatempo ${ }^{9}$.

A caricatura, um gênero que combina arte, crítica e humor, fornece um rico e pouco explorado material que possibilita compreender as relações sociais, culturais e políticas de uma sociedade.

\section{Referências Bibliográficas}

ANDRADE, Joaquim M. F. de. História da Fotorreportagem no Brasil: a fotografia na imprensa do Rio de Janeiro de 1839 a 1900. Rio de Janeiro: Elsevier, 2004

\footnotetext{
${ }^{8}$ FONSECA, 1999. Op. Cit., p.12

${ }^{9}$ FONSECA, 1999. Op. Cit., p.13
} 
FONSECA, Joaquim da. Caricatura: a imagem gráfica do humor. Artes e Ofícios Editora Ltda.: Porto Alegre, 1999

PISANI, Osmar. Arte Catarinense: uma paisagem em transformação. In: CORREA, Carlos Humberto P. Et al. (org.). A realidade catarinense no século $\mathbf{X X}$. Florianópolis: Instituto Histórico e Geográfico de Santa Catarina, 2000.

McPHEE, Constance et ORENSTEIN, Nadine (org.). Infinite Jest: caricature and satire from Leonardo to Levine. The Metropolitan Museum of Art: New York, 2011

SIEBERT, Itamar. Critica jornalística, sociabilidade e vida familiar na Desterro de meados do século XIX. In: BRANCHER, Ana e AREND, Silvia Mara Favero (org.). História de Santa Catarina no século XIX. Florianópolis: Ed. Da UFSC, 2001

VASARI, Giorgio. Vida dos artistas. Edição de Lorenzo Torrentino. São Paulo: Editora WMF Martins Fonte, 2011. 